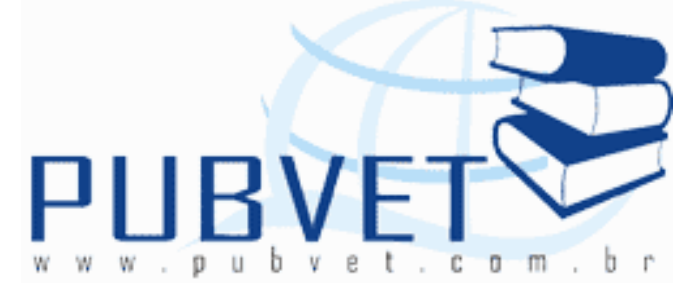

PUBVET, Publicações em Medicina Veterinária e Zootecnia.

\title{
Aplicação de adubo em milho verde orgânico irrigado
}

\section{Leandro Barradas Pereira ${ }^{1}$, Lauro Kenji Komuro ${ }^{1}$, Neli Cristina Belmiro dos} Santos $^{2}$, Lilian Christian Domingues de Souza ${ }^{3}$, Aline Estela Zini de Oliveira ${ }^{3}$, Alício José Corbucci Moreira ${ }^{3}$ e Cláudia Mitidiero Stachissini Arcain³, Francislene Andrea Berti Rossi ${ }^{3}$

${ }^{1}$ Pós-graduandos da Faculdade de Engenharia de Ilha Solteira/UNESP, Ilha Solteira, SP. Ibpereira25@hotmail.com e komurolk@ig.com.br,

${ }^{2}$ Agência Paulista de Tecnologia dos Agronegócios/Extremo Oeste, Andradina, SP.neli@apta.sp.gov.br,

${ }^{3}$ Escola Técnica Estadual, Andradina-SP (Centro Paula Souza), lilianagronomia90@hotmail.com, aline.oliveira301@etec.sp.gov.br, aliciomedvet@ig.com.br e claudia.arcain@etec.sp.gov.br.

\section{Resumo}

O cultivo de milho verde orgânico está em fase de expansão, visando produzir um alimento sustentável, estando associado à agricultura familiar, promovendo o desenvolvimento social e econômico desse sistema de produção. $O$ objetivo do presente trabalho foi avaliar a influência das doses de adubo nas produtividades de milho verde em sistema orgânico no município de Andradina-SP. Para tanto, foi desenvolvido um experimento de campo na Escola Técnica Estadual, em Andradina-SP, no ano de 2011. O delineamento experimental foi de blocos casualizados, contendo cinco doses do adubo 
PEREIRA, L.B. et al. Aplicação de adubo em milho verde orgânico irrigado. PUBVET, Londrina, V. 7, N. 4, Ed. 227, Art. 1502, 2013.

orgânico (2,0 sem silício; 2,0;4,0; 6,0 e 8,0 com silício t ha $\left.{ }^{-1}\right)$ e uma cultivar de milho (Biomatrix 3061), com quatro repetições. As doses do adubo orgânico não influenciaram o desenvolvimento e produtividade de espigas verdes, porém os resultados verificados foram semelhante ao cultivo convencional, tornando a cultura do milho verde orgânico viável técnica e economicamente na região de Andradina-SP, visando à agricultura familiar.

Palavras-chave: composto orgânico, agroecologia, Zeamays L.

\section{Application of fertilizer on irrigated organic corn}

\section{Abstract}

Growing organic corn is in expansion, aiming at producing sustainable food, being associated with family agriculture, promoting social and economical development of this production system. This study aimed at evaluating the influence of the amount of fertilizer in the yield of corn crops in organic system in the city of Andradina - SP. For that, there was a field experiment at the State Technical School, in Andradina - SP, in 2011. The experimental delineation was random blocks, containing five doses of organic fertilizer $(2,0$ without silicon; 2,$0 ; 4,0 ; 6,0$ and 8,0 with silicon t ha-1) and a corn varieties (Biomatrix 3061), with four repetitions. The doses of organic fertilizer did not influence the development and yield of green cobs, and the results were similar to those of conventional crops, making the growing of organic corn technically and economically viable in the region of Andradina - SP, focusing on family agriculture.

Keywords: organic compound, agroecology, Zesmays L.

\section{Introdução}

A sustentabilidade é tema relevante no século XXI, portanto produzir alimentos orgânicos está em ampla expansão em âmbito mundial, e atende à crescente demanda por parte dos consumidores mais exigentes.A produção de milho verde orgânico absorve, principalmente, mão-de-obra familiar, que 
PEREIRA, L.B. et al. Aplicação de adubo em milho verde orgânico irrigado. PUBVET, Londrina, V. 7, N. 4, Ed. 227, Art. 1502, 2013.

segundo Cruz et al. (2006) contribui para a geração de empregos em pequenas e médias propriedades, particularmente na época da colheita, que é realizada de forma manual. Dentro desse novo sistema de produção, a adubação da cultura necessita de novas tecnologias para que se torne viável a produção técnica e econômica. Malavolta (2002) relata que a adubação orgânica é feita através da utilização de vários tipos de resíduos, tais como: esterco curtido, vermicomposto de minhocas, compostos fermentados, biofertilizantes enriquecido com micronutrientes e cobertura morta. Todos esses materiais são ricos em organismos úteis, macro e micronutrientes, antibióticos naturais e substâncias de crescimento. Não há registros de uso, no solo, de compostos orgânicos elaborados a partir de resíduos de frigoríficos. No entanto, Mantovani et al. (2005) afirmam que a aplicação sistemática de outros compostos orgânicos tem efeito sobre propriedades químicas, físicas e biológicas do solo, sendo que a aplicação de matéria orgânica e nutriente ao solo via restos agroindustriais e compostos orgânicos, é prática comum na agropecuária, trazendo como ganhos o aumento da CTC, nitrogênio e fósforo.

No Brasil, existem estudos com milho verde orgânico que se referem mais ao comportamento de cultivares, sendo o emprego de adubos orgânicos pouco mencionados possivelmente, em razão de o manejo seguir as mesmas recomendações para o milho grão.

A partir dessas considerações, o objetivo do presente trabalho foi avaliar a influência das doses de adubo nas produtividades de milho verde em sistema orgânico no município de Andradina-SP, visando à agricultura familiar.

\section{Material e Métodos}

O experimento foi desenvolvido na Escola Técnica Estadual, no município de Andradina-SP, localizado na região noroeste do Estado de São Paulo a 379 metros de altitude, latitude $20^{\circ} 58^{\prime} \mathrm{S}$ e longitude $51^{\circ} 19^{\prime} \mathrm{W}$. O clima, segundo a classificação Köpen é tropical quente e úmido com inverno seco. A precipitação média anual é de $1.150 \mathrm{~mm}$, a temperatura média anual é de $23^{\circ} \mathrm{C}$ e a umidade relativa do ar entre 70 e $80 \%$ (SANTOS, 2007) e o solo classificado 
PEREIRA, L.B. et al. Aplicação de adubo em milho verde orgânico irrigado. PUBVET, Londrina, V. 7, N. 4, Ed. 227, Art. 1502, 2013.

como Argissolo. Antes da instalação do experimento foram coletadas amostras de solo da área experimental e realizada análise química que revelou os seguintes valores: $\mathrm{P}=6 \mathrm{mg} \mathrm{dm}{ }^{-3} ; \mathrm{pH}\left(\mathrm{CaCl}_{2}\right)=4,9 ; \mathrm{M} . \mathrm{O} .=12 \mathrm{~g} \mathrm{dm}^{-3} ; \mathrm{K}^{+}=2,2$ $\mathrm{mmol}_{\mathrm{c}} \mathrm{dm}^{-3} ; \mathrm{Ca}^{+2}=9 \mathrm{mmol}_{\mathrm{c}} \mathrm{dm}^{-3} ; \mathrm{Mg}^{+2}=6 \mathrm{mmol}_{\mathrm{c}} \mathrm{dm}^{-3} ; \mathrm{H}+\mathrm{Al}=18 \mathrm{mmol}_{\mathrm{c}} \mathrm{dm}^{-}$ $3, \mathrm{CTC}=35,2$ e $\mathrm{V}=49 \%$.

O delineamento experimental foi de blocos casualizados, contendo cinco doses do adubo orgânico ( 2,0 sem silício; 2,$0 ; 4,0 ; 6,0$ e 8,0 com silício t ha-1 $\left.{ }^{-1}\right)$ e uma cultivar de milho (Biomatrix 3061), com quatro repetições. As parcelas foram constituídas por quatro linhas de milho espaçadas de 0,8 m entre si com $5,0 \mathrm{~m}$ de comprimento com 5 plantas por metro. Dentro da parcela foram consideradas como área útil as duas linhas centrais desprezando-se 0,5 $\mathrm{m}$ das extremidades. O milho foi semeado manualmente em agosto de 2011, utilizando-se a população de 62 mil plantas ha-1. O fornecimento de água foi realizado pelo sistema de irrigação por aspersão. A adubação foi realizada com

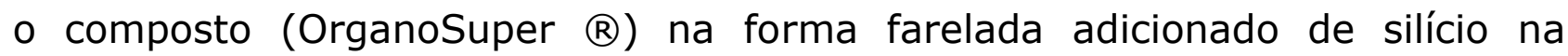
proporção (3 partes organosuper:1parte de sílicio), apresentando o adubo aproximadamente $50 \%$ de matéria orgânica, $\mathrm{P}$ de 2 a $4 \%, \mathrm{~N}$ de 3 a $5 \%, \mathrm{~K}$ de 0,7 a $1,5 \%$ e relação $\mathrm{C} / \mathrm{N}$ de $10 / 1$. A adubação de cobertura foi realizada com 15 DAE das plantas com $50 \mathrm{~kg} \mathrm{ha}^{-1} \mathrm{de} \mathrm{N}$ na forma de composto orgânicoOrganoSuper $\AA$ farelado. $O$ controle de pragas foi efetuado com três aplicações de óleo de Nim a 0,5\%. Por ocasiões das pulverizações foram efetuadas adubações foliares alternadamente com humissolve a $1 \%$ e fertish a $1 \%$. O controle de plantas daninhas em ambos os cultivos foi efetuado através de capina manual aos 15 e 35 DAE.

Foram realizadas as avaliações: a) crescimento (altura plantas, altura da primeira espiga e diâmetro do colmo); b) produtividade de espigas verdes (númerototal e comercial de espigas, massa das espigas com palha e despalhadas); c) características das espigas verdes (diâmetro e comprimento médio) e d) massa verde plantas sem espigas e massa verde total.

Os dados foram submetidos à análise de variância, utilizando-se o teste $\mathrm{F}$ e a análise de regressão. 
PEREIRA, L.B. et al. Aplicação de adubo em milho verde orgânico irrigado. PUBVET, Londrina, V. 7, N. 4, Ed. 227, Art. 1502, 2013.

\section{Resultados e Discussão}

A altura de plantas, de primeira espiga e o diâmetro do colmo não foram influenciadas pelas doses de adubo. O diâmetro do colmo é uma característica de grande importância, pois plantas com maior diâmetro basal são menos sujeitas ao tombamento e quebramento e facilitam a colheita do milho verde. A altura média das plantas ficou em torno de 193,03cm, altura da primeira espiga foi de $107,43 \mathrm{~cm}$ e o diâmetro $2,11 \mathrm{~cm}$.

Tabela 1. Médias de altura de plantas, altura da primeira espiga e diâmetro do colmo de milho cultivado em sistema orgânico.

\begin{tabular}{lccc}
\hline $\begin{array}{c}\text { Doses do adubo } \\
\text { t/ha } \mathbf{- 1}\end{array}$ & $\begin{array}{c}\text { Altura de } \\
\text { plantas } \mathbf{( c m})\end{array}$ & $\begin{array}{c}\text { Altura da primeira } \\
\text { espiga } \mathbf{( c m})\end{array}$ & $\begin{array}{c}\text { Diâmetro do colmo } \\
\text { (cm) }\end{array}$ \\
\hline 2,0 (controle) & 176,20 & 106,65 & 2,25 \\
2,0 (silício) & 195,67 & 104,30 & 2,07 \\
4,0 (silício) & 185,47 & 102,55 & 2,04 \\
6,0 (silício) & 205,80 & 113,35 & 1,94 \\
8,0 (silício) & 202,00 & 110,32 & 2,24 \\
\hline C.V. \% & 16,41 & 9,30 & 6,34 \\
$\mathrm{R}^{2}$ & n.s. & n.s. & n.s. \\
\hline
\end{tabular}

n.s. Não significativo. $* *$ Regressão significativa a $1 \%$ de probabilidade. ${ }^{*}$ Regressão significativa a $5 \%$ de probabilidade.

Quanto às médias do número total e comercial de espigas e massa de espigas com palha e sem palha,embora não tenham apresentado diferenças significativas, nota-se queo número total espigas e o número espigas comerciaisna dose $2 \mathrm{t} \mathrm{ha}^{-1}$ (presença silício) foram maiores, $57.812 \mathrm{~kg} \mathrm{ha}^{-1} \mathrm{e}$ $48.437 \mathrm{~kg} \mathrm{ha}^{-1}$, respectivamente.

A produtividade média alcançada ficou em torno de56 mil espigas por hectare, $7.332 \mathrm{~kg}$ por hectare de espigas despalhadas. Os resultados de produtividade em cultivo orgânico deste trabalho são semelhantes aos obtidos por Santos et al. (2005) porém utilizando doses maiores de adubação (30 t ha' ${ }^{1}$ de esterco bovino). No entanto, Cruzetal. (2010) estudando cultivares de milho verde sob cultivo orgânico obtiveram produtividades menores, da ordem 
PEREIRA, L.B. et al. Aplicação de adubo em milho verde orgânico irrigado. PUBVET, Londrina, V. 7, N. 4, Ed. 227, Art. 1502, 2013.

de 33 milespigas comerciaisha ${ }^{-1}$ e 49 mil espigas ha ${ }^{-1}$ utilizando 12 t de esterco aviário ha ${ }^{-1}$.

Tabela 2. Médias de número total e comercial de espigas, massa de espigas com palha e despalhadas de milho cultivado em sistema orgânico.

\begin{tabular}{lcccc}
\hline $\begin{array}{c}\text { Doses do } \\
\text { adubo t/ha-1 }\end{array}$ & $\begin{array}{c}\text { Número total } \\
\text { de espigas } \\
\text { ha-1 }^{-1}\end{array}$ & $\begin{array}{c}\text { Número de } \\
\text { espigas } \\
\text { comerciais ha }\end{array}$ & $\begin{array}{c}\text { Massa de } \\
\text { espigas com } \\
\text { palha kg ha }\end{array}$ & $\begin{array}{c}\text { Massa de } \\
\text { espigas } \\
\text { despalhadas } \\
\text { kg ha }^{-1}\end{array}$ \\
\hline 2,0 (controle) & 55859 & 47656 & 14070 & 8071 \\
2,0 (silício) & 57812 & 48437 & 12523 & 7260 \\
4,0 (silício) & 55078 & 47656 & 12177 & 6941 \\
6,0 (silício) & 54687 & 44531 & 11796 & 6675 \\
8,0 (silício) & 56640 & 47656 & 13431 & 7716 \\
\hline CV \% & 14,74 & 20,33 & 19,47 & 25,99 \\
$\mathrm{R}^{2}$ & n.s. & n.s. & n.s. & n.s. \\
\hline
\end{tabular}

n.s. Não significativo. **Regressão significativa a $1 \%$ de probabilidade. *Regressão significativa a $5 \%$ de probabilidade.

$\mathrm{Na}$ colheita de milho verde nem todas as espigas são comercializáveis, havendo uma produção de palhada e espigas não comercializáveis que poderão ser utilizados como forragem. Os rendimentos de massa verde total sem espigas e massa verde total das plantas não apresentaram diferenças significativas. Observa-se que a média da massa verde total sem espigas foi de $26.246 \mathrm{~kg} \mathrm{ha}^{-1} \mathrm{e}$ a média da massa verde total das plantas de $39.046 \mathrm{~kg} \mathrm{ha}^{-1}$.

Os valores referentes ao diâmetro basal e ao comprimento da espiga verde não apresentaram diferenças significativas, tendo médias de 4,21 e $16,63 \mathrm{~cm}$, respectivamente. Esses resultados foram comparáveis àqueles encontrados por Devide (2006), ao estudar o cultivo orgânico consorciado do milho (cv. Eldorado) com o aipim-de-mesa (cv. IAC 576-70), e semelhantes também aos resultados de Guedes et al. (2010). O diâmetro basal e comprimento de espigas comerciais exigido pelo mercado interno é de aproximadamente 4 e $15 \mathrm{~cm}$, respectivamente, apresentando os resultados do presente trabalho dentro dos padrões. 
PEREIRA, L.B. et al. Aplicação de adubo em milho verde orgânico irrigado. PUBVET, Londrina, V. 7, N. 4, Ed. 227, Art. 1502, 2013.

Tabela 3. Médias da massa verde total sem espigas, massa verde total das plantas, diâmetro e comprimento de espigas comerciais de milho cultivado em sistema orgânico.

\begin{tabular}{lcccc}
\hline $\begin{array}{c}\text { Doses do } \\
\text { adubo t/ha-1 }\end{array}$ & $\begin{array}{c}\text { Massa verde } \\
\text { total sem } \\
\text { espigas kg } \\
\text { ha-1 }^{-1}\end{array}$ & $\begin{array}{c}\text { Massa } \\
\text { verde total } \\
\text { das plantas } \\
\text { kg ha }^{-1}\end{array}$ & $\begin{array}{c}\text { Diâmetro } \\
\text { basal espiga } \\
\mathbf{( c m )}\end{array}$ & $\begin{array}{c}\text { Comprimento } \\
\text { espiga } \\
\mathbf{( c m )}\end{array}$ \\
\hline 2,0 (controle) & 28421 & 42492 & 4,35 & 17,01 \\
2,0 (silício) & 24929 & 37453 & 4,18 & 16,30 \\
4,0 (silício) & 25250 & 37427 & 4,17 & 17,68 \\
6,0 (silício) & 23968 & 35765 & 4,09 & 15,32 \\
8,0 (silício) & 28664 & 42095 & 4,27 & 16,83 \\
\hline C.V. \% & 19,73 & 15,34 & n,36 & 7,27 \\
$\mathrm{R}^{2}$ & n.s. & n.s. & n.s. & n.s. \\
\hline
\end{tabular}

n.s. Não significativo. **Regressão significativa a $1 \%$ de probabilidade. *Regressão significativa a $5 \%$ de probabilidade

Constatou-se uma boa produtividade da cultura em sistema orgânico mesmo com doses menores do adubo orgânico. Assim, como Cruz et al. (2006) que relatam a viabilidade da adubação orgânica no fornecimento de nutrientes para o milho, que ao longo dos anos proporcionam rendimentos semelhantes e até superiores aos obtidos comercialmente, além de elevar a fertilidade do solo contribuindo para a sustentabilidade da produção.

\section{Conclusão}

As doses do adubo orgânico não influenciaram o desenvolvimento e produtividade do milho verde orgânico.As produtividades alcançadas no sistema de cultivo orgânico foram semelhantes ao cultivo convencional, tornando a cultura viável técnica e economicamente para a agricultura familiar.

\section{Literatura Citada}

CRUZ, J. C.; KONZEN, E.A.; FILHO, I. A. P.; MARRIEL, I.E.; CRUZ, E.; DUARTE, J.O.; OLIVEIRA, M.F.; ALVARENGA, R.C. Produção de milho orgânico na agricultura Familiar. Sete Lagoas: Embrapa-CNPMS, 17p. (Embrapa-CNPMS, Comunicado Técnico, 81), 2006.

CRUZ, J.C.; PEREIRA FILHO, I.A.; MOREIRA, J.A.A.; MATRANGOLO, W.J.R.Resposta de Cultivares de Milho à Adubação Orgânica para Consumo Verde, Grãos e Forragem em Sistema Orgânico de Produção. In: XXVIII Congresso Nacional de Milho e Sorgo, 2010, Goiânia: Associação Brasileira de Milho e Sorgo. CD-ROM. 
DEVIDE A.C.P. Sistema orgânico de produção de mandioca consorciada com milho e caupi. Tese de mestrado, 85p. UFRRJ, Seropédica,2006.

GUEDES, R.E.; RUMJANEK, N.G.; XAVIER, G.R.; GUERRA, J.G.M.; RIBEIRO, R.L.D. Consórcios de caupi e milho em cultivo orgânico para produção de grãos e espigas verdes. Horticultura brasileira, v.28, p.174-177, 2010.

MALAVOLTA, E. ABC da Adubação. $4^{\circ}$ ed. SãoPaulo: Editora Agronômica "Ceres" LTDA. 2002. 256p.

MANTOVANI, J.R.; FERREIRA, M.E.; CRUZ, M.C.P.; BARBOSA, J.C. Alterações nos atributos de fertilidade em solo adubado com composto de lixo urbano. Revista Brasileira deCiência do Solo, Viçosa, MG, v.29, n.5, p.817-824, 2005.

SANTOS, I.C.; MIRANDA, G.V.; MELO, A.V.; MATTOS, R.N.; OLIVEIRA, L.R.; LIMA, J.S.; GALVÃO, J.C.C. Comportamento de cultivares de milho produzidos organicamente e correlações entre características das espigas colhidas no estádio verde. Revista Brasileira de Milho e Sorgo, v.4, p.45-63, 2005.

SANTOS, N. C. B. Comportamento de cultivares de feijoeiro e de milho verde em cultivo solteiro e consorciado. Tese de doutorado, 98 p. UNESP, Ilha Solteira, 2007. 